\title{
Circulating progastrin-releasing peptide in the diagnosis of Small Cell Lung Cancer (SCLC) and in therapeutic monitoring
}

\author{
Vittoria Barchiesi ${ }^{1}$, Vittorio Simeon ${ }^{2}$, Claudia Sandomenico ${ }^{3}$, Monica Cantile4, Dionigio Cerasuolo ${ }^{5}$, Paolo Chiodini ${ }^{2}$, \\ Alessandro Morabito ${ }^{3}$, Ernesta Cavalcanti ${ }^{5}$ \\ ${ }^{1}$ Department "Campania Centro", A.O.R.N. "Antonio Cardarelli", Napoli - Italy \\ ${ }^{2}$ Medical Statistics Unit, University of Campania "Luigi Vanvitelli", Napoli - Italy \\ ${ }^{3}$ Thoracic Medical Oncology Unit, Istituto Nazionale Tumori IRCCS, "Fondazione G.Pascale", Napoli - Italy \\ ${ }^{4}$ Pathology Unit, Istituto Nazionale Tumori IRCCS, "Fondazione G.Pascale", Napoli - Italy \\ 5Laboratory Medicine Unit, Istituto Nazionale Tumori IRCCS, "Fondazione G.Pascale", Napoli - Italy
}

\begin{abstract}
Introduction: Progastrin-releasing peptide (proGRP), a precursor of GRP, has been recently reported as a putative circulating biomarker for differential diagnosis between non-small cell lung cancer (NSCLC) and SCLC. We evaluated the diagnostic effectiveness of proGRP to differentiate patients with NSCLC and SCLC and the usefulness of combined measurement of proGRP and neuron-specific enolase (NSE) for diagnosing SCLC.

Methods: Serum proGRP, NSE, cytokeratin 19 fragment 21-1 (CYFRA 21.1), squamous cell carcinoma antigen (SCC $\mathrm{Ag}$ ) and carcinoembryonic antigen (CEA) were prospectively collected and measured in patients with a new diagnosis of lung cancer. Serum proGRP was also measured in healthy subjects. The serum proGRP, NSE, CYFRA 21.1 and CEA concentrations were determined by an electrochemiluminescence immunoassay and the serum SCC Ag concentration was determined by an automated immunofluorescence assay. Differences between proGRP and NSE in patients with SCLC and NSCLC were evaluated and compared using Mann-Whitney test.

Results: A total of 77 patients affected by SCLC $(n=17)$ and NSCLC $(n=60)$ were enrolled in the present study. Moreover, 50 cases of healthy subjects were analyzed for proGRP. SCLC patients showed a significantly higher proGRP $(1,484 \mathrm{pg} / \mathrm{mL}$; range $168-3,777)$ levels compared to NSCLC patients $(45 \mathrm{pg} / \mathrm{mL}$; range 31.7-60.6), $\mathrm{p}<0.0001$. In healthy subjects the median proGRP level was $36.1(28.8-43.5) \mathrm{pg} / \mathrm{mL}$, significantly lower than SCLC patients. ProGRP showed a higher specificity when compared to NSE, with a difference in proportion of $47.5 \%$ (95\% confidence interval $32.5 \%$ to $62.5 \%, p<0.001$ ). Serial measurements of proGRP in SCLC patients showed a decrease in responsive chemotherapy patients.
\end{abstract}

Conclusions: ProGRP is an accurate biomarker for diagnosis of SCLC and for discrimination of SCLC from NSCLC.

Keywords: Lung cancer, proGRP, Serum biomarker

\section{Introduction}

Lung cancer is one of the most common and malignant tumors, with high morbidity and mortality worldwide, and its incidence has been increasing, especially among women, in the last decades $(1,2)$. The early diagnosis and accurate staging of lung cancer for immediate and appropriate treatment

Received: November 23, 2020

Accepted: June 15, 2021

Published online: July 7, 2021

\section{Corresponding author:}

Ernesta Cavalcanti

Laboratory Medicine Unit

Istituto Nazionale Tumori IRCCS, "Fondazione G.Pascale"

80100 Napoli - Italy

e.cavalcanti@istitutotumori.na.it are among the main strategies to improve survival rates (3). The first step in the diagnosis is to distinguish between nonsmall cell lung cancer (NSCLC) and SCLC, which has a poorer prognosis $(4,5)$. Despite lung cancer diagnosis being only based on histology, different serum biomarkers have been proven to be useful tools for the diagnosis, prognosis and follow-up, but there are currently no guidelines or standards on their application in clinical practice $(6,7)$. The National Academy of Clinical Biochemistry (NACB) Laboratory Medicine Practice Guidelines (8) recommend carcinoembryonic antigen (CEA), squamous cell carcinoma-related antigen (SCC$\mathrm{Ag}$ ), neuron-specific enolase (NSE), cytokeratin 19 fragment 21-1 (CYFRA 21.1), carbohydrate antigen 125 (CA 125) and progastrin-releasing peptide (proGRP) as routine markers of lung cancer. NSE is considered the tumor marker of choice in SCLC diagnosis, but it is not pathognomonic because its effectiveness is related to the stage of the tumor (9). 
ProGRP is a precursor of gastrin-releasing peptide (GRP), an active hormone involved in the physiological digestive process. GRP is a 27-amino-acid peptide homologous to the C-terminal of bombesin isolated from porcine stomach, in fetal as well as neonatal lung tissue and in primary lung cancer, particularly in SCLC (10-13).

GRP cannot be used as a biomarker due to its instability (half-life of GRP is $2 \mathrm{~min}$ ), while proGRP is a stable protein with a half-life of 19-28 days. Recently, circulating proGRP has been reported as a putative biomarker for differential diagnosis between NSCLC and SCLC (14-18).

The aim of the present study was to evaluate the diagnostic effectiveness of proGRP to differentiate patients with NSCLC and SCLC, the usefulness of combined measurement of proGRP and NSE for the diagnosis of SCLC, the comparison of diagnostic efficacy of proGRP vs. a combined panel of tumor markers and to establish the reference values of proGRP in healthy patients.

\section{Methods}

\section{Patients}

Serum proGRP, NSE, CYFRA 21.1, SCC Ag and CEA were prospectively collected and measured in patients with a new diagnosis of lung cancer admitted to the Thoracic Medical Oncology of the National Cancer Institute "G. Pascale" of Naples.

Moreover, serum proGRP was measured in healthy subjects collected at the Unit of Transfusional Medicine of the National Cancer Institute "G. Pascale" of Naples.

The present study was approved through the Ethics Committee and all patients completed an informed consent.

\section{Assay}

Serum samples were taken in Vacutainer tube SST II Advance and analyzed in less than 1 hour. Serum proGRP, NSE, CYFRA 21.1 and CEA concentrations were determined by an electrochemiluminescence immunoassay on a Cobas C6000 automated analyzer (Roche Diagnostics). Serum SCC Ag concentration was determined by an automated immunofluorescence assay on Kryptor compact plus (Thermo Scientific). For all analytes the reference range was set according to the data sheet manufacturer.

\section{Statistical Analysis}

Data were described as reported: continuous variables as mean and standard deviation, or median and interquartile range if distribution was not symmetric; categorical variables as number and percentage. Differences of diagnostic markers proGRP and NSE in patients with SCLC and NSCLC were evaluated and compared using Mann-Whitney test. Successively, proGRP and NSE were categorized and defined positive using these criteria: cutoff $>100 \mathrm{pg} / \mathrm{mL}$ for proGRP; $>17 \mathrm{ng} / \mathrm{mL}$ for NSE. Furthermore, the algorithm proposed by Molina et al. (19), taking into consideration SCC, proGRP, NSE, CYFRA and CEA, was used to classify patients. For each biomarker (proGRP, NSE and algorithm), the diagnostic measures, such as sensitivity, specificity, positive predictive value (PPV) and negative predictive value (NPV), were calculated to evaluate the accuracy in discriminating SCLC from NSCLC. Pairwise comparison of diagnostic measures was performed using McNemar's test (20). Receiver operating characteristic (ROC) curve analysis was calculated to define new threshold values for proGRP and NSE in our population. The area under the ROC curve (AUC) was used to quantify accuracy and define sensitivity and specificity. For descriptive purpose, proGRP values (in log scale) in SCLC patients were collected and reported for the whole treatment period. All tests were two-tailed and a p-value $<0.05$ was considered statistically significant. All data were analyzed using $\mathrm{R}$ software 3.3.1 ( $R$ foundation for Statistical Computing, Vienna, Austria).

\section{Results}

\section{ProGRP serum level in lung cancer patients}

A total of 77 patients affected by lung cancer, 17 SCLC and 60 NSCLC, were enrolled in the present study between July 2015 and July 2017; moreover, 50 cases of healthy subjects were collected from the Unit of Transfusional Medicine, at the National Cancer Institute "G. Pascale" of Naples, Italy.

The study design is shown in Figure 1.

The mean age of the 17 SCLC patients was $63.4 \pm 8.6$ years and there were $10(58.8 \%)$ male and 7 (41.2\%) female patients. The 60 NSCLC patients were older (68.4 \pm 9.1 years) and with higher proportion of male patients (65\%) (Tab. I).

The median (interquartile range [IQR]) proGRP level in the total population was $47.3(34.3-87.3) \mathrm{pg} / \mathrm{mL}$. SCLC patients showed (Tab. I and Fig. 2) a significantly higher proGRP $(1,484$ $[168-3,777] \mathrm{pg} / \mathrm{mL}$ ] levels compared to NSCLC patients (45 [31.7-60.6] pg/mL) (Mann-Whitney test, $\mathrm{p}<0.0001$ ). In addition, NSE was significantly higher in SCLC than NSCLC patients

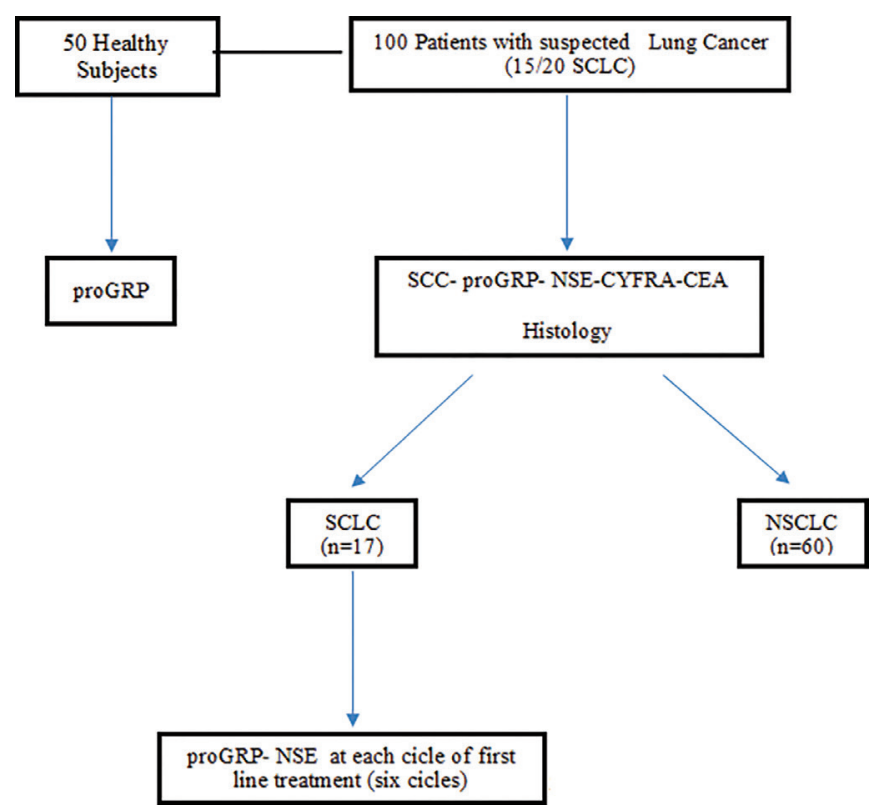

Fig. 1 - Flow chart of the study design. 
TABLE I - Patients' characteristics and values of different analytes

\begin{tabular}{|c|c|c|c|}
\hline & $\begin{array}{l}\text { Total patients } \\
\quad(\mathrm{n}=77)\end{array}$ & $\begin{array}{c}\text { SCLC } \\
\text { (n=17, 22\%) }\end{array}$ & $\begin{array}{c}\text { NSCLC } \\
(n=60,78 \%)\end{array}$ \\
\hline \multicolumn{4}{|l|}{ Age, years } \\
\hline Mean (SD) & $67.3(9.16)$ & $63.4(8.6)$ & $68.4(9.11)$ \\
\hline \multicolumn{4}{|l|}{ Sex, n (\%) } \\
\hline Female & $28(36.40)$ & $7(41.2)$ & $21(35.00)$ \\
\hline Male & $49(66.60)$ & $10(58.8)$ & $39(65.00)$ \\
\hline \multicolumn{4}{|c|}{ Creatinine, $\mathrm{mg} / \mathrm{dL}$} \\
\hline Median (IQR) & $0.82(0.67-0.93)$ & $0.82(0.68-0.9)$ & $0.82(0.66-0.96)$ \\
\hline \multicolumn{4}{|l|}{ LDH, U/L } \\
\hline Median (IQR) & $418(336-560)$ & 510 (376-633) & 415 (330-543) \\
\hline \multicolumn{4}{|l|}{ AST, U/L } \\
\hline Median (IQR) & $17(13-22)$ & $17(13-22.5)$ & $17(14-22)$ \\
\hline \multicolumn{4}{|l|}{ ALT, U/L } \\
\hline Median (IQR) & $16(12-25)$ & $16(11-20)$ & $16(12-26)$ \\
\hline \multicolumn{4}{|l|}{ Bilirubin, mg/dL } \\
\hline Median (IQR) & $0.5(0.4-0.7)$ & $0.5(0.4-0.6)$ & $0.5(0.4-0.7)$ \\
\hline \multicolumn{4}{|l|}{ CEA, ng/mL } \\
\hline Median (IQR) & 7.9 (3.1-38.9) & $4.6(3-17.9)$ & $8.7(3-42.6)$ \\
\hline \multicolumn{4}{|l|}{ CYFRA, ng/mL } \\
\hline Median (IQR) & $5.4(3.2-12.7)$ & $3.4(2.3-6.4)$ & $7(3.3-13.7)$ \\
\hline \multicolumn{4}{|l|}{ NSE, ng/mL } \\
\hline Median (IQR) & $19(14.2-27.6)$ & 55 (34-107.4) & $17.7(13-24)$ \\
\hline \multicolumn{4}{|l|}{$\mathrm{SCC}, \mathrm{ng} / \mathrm{mL}$} \\
\hline Median (IQR) & $0.5(0.1-0.8)$ & $0.2(0.1-0.6)$ & $0.5(0.2-1.1)$ \\
\hline \multicolumn{4}{|l|}{ proGRP, pg/mL } \\
\hline Median (IQR) & $47.3(34.3-87.3)$ & $1484(168-3777)$ & $45(31.7-60.6)$ \\
\hline \multicolumn{4}{|l|}{ proGRP $(\log 10)$} \\
\hline Mean (SD) & $1.9(0.8)$ & $3(1)$ & $1.7(0.3)$ \\
\hline
\end{tabular}

$\mathrm{ALT}=$ alanine aminotransferase; $\mathrm{AST}=$ aspartate transaminase; $\mathrm{CEA}=$ carcinoembryonic antigen; CYFRA 21.1 = cytokeratin 19 fragment 21-1; IQR = interquartile range; $\mathrm{LDH}=$ lactate dehydrogenase; $\mathrm{NSCLC}=$ non-small cell lung cancer; NSE = neuron-specific enolase; proGRP = precursor of gastrin-releasing peptide; $\mathrm{SCC}=$ squamous cell carcinoma; $\mathrm{SCLC}=$ small cell lung cancer; $\mathrm{SD}=$ standard deviation
(55 [34-107.4] ng/mL versus 17.7 [13-24] $\mathrm{ng} / \mathrm{mL}$ ), whereas CYFRA 21.1 was lower in SCLC patients. There were no differences for CEA and SCC biomarkers.

In healthy subjects the median proGRP level was 36.1 (28.8-43.5) $\mathrm{pg} / \mathrm{mL}$, significantly lower than SCLC patients (data not shown).

\section{ProGRP and NSE in lung cancer histological types and therapeutic response}

Diagnostic accuracy of each biomarker is reported in Table II. According to lung cancer histological type, proGRP showed a sensitivity of $82.4 \%$ (95\% confidence interval [Cl], 56.6-96.2) with a specificity of $93.3 \%(95 \% \mathrm{Cl}, 83.8-98.2)$. PPV and NPV were $77.8 \%$ and $94.9 \%$, respectively. NSE biomarker and algorithm (NSE + proGRP) showed the following value of accuracy: sensitivity ( $100 \%$ and $86.7 \%$, respectively), specificity (45\% and $96.6 \%$, respectively), PPV (34\% and $86.7 \%$, respectively) and NPV (100\% and $96.6 \%$, respectively). Pairwise comparison of proGRP with NSE and algorithm highlighted no differences in terms of sensitivity. ProGRP showed a higher specificity when compared to NSE, with a difference in proportion of $47.5 \%(95 \% \mathrm{Cl} 32.5 \%$ to $62.5 \%$, Exact McNemar's test $\mathrm{p}<0.001$ ). ProGRP and algorithm measures revealed a similar performance for both of them.

On ROC curve analysis, AUC for proGRP and NSE was comparable with $0.86(95 \% \mathrm{Cl}, 0.71-1)$ and $0.92(95 \% \mathrm{Cl}, 0.84-$ 0.99), respectively (Fig. 3).

Serial measurements of proGRP in 12 SCLC patients showed a decrease in responsive patients and they are depicted in Figure 4.

\section{Discussion}

In our study, median proGRP levels were significantly higher in patients with SCLC than in those with NSCLC or healthy subjects. Plasma proGRP at cutoff level of $100 \mathrm{pg} / \mathrm{mL}$ showed a high sensitivity and specificity (82.4\% and $93.3 \%$, respectively) in identifying patients with SCLC, with a specificity higher than NSE. PPV and NPV were $77.8 \%$ and $94.9 \%$, respectively. Moreover, responsive patients presented a decrease in proGRP levels. These results confirm the accuracy of proGRP in clinical practice in the diagnosis of SCLC.

In 2011, a meta-analysis of 5,146 patients enrolled in 11 clinical trials, including 1,095 with SCLC, concluded that
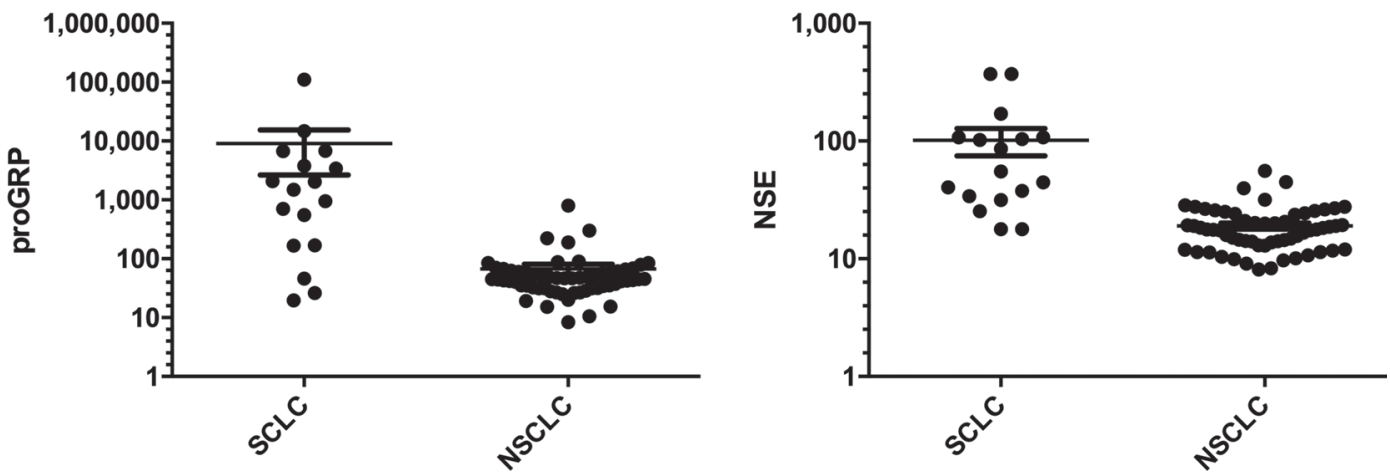

Fig. 2 - ProGRP and NSE levels in SCLC and NSCLC. On the left: proGRP level in SCLC and NSCLC patients; on the right: NSE level in SCLC and NSCLC patients. NSCLC = non-small-cell lung cancer; NSE = neuron-specific enolase; proGRP = progastrinreleasing peptide; SCLC = small cell lung cancer. Values were reported in $\log 10$ scale. 
TABLE II - Diagnostic accuracy of proGRP, NSE and their combination in discriminating SCLC from NSCLC

\begin{tabular}{lcccc}
\hline & Sn & Sp & PPV & NPV \\
\hline proGRP & $82.4(56.6-96.2)$ & $93.3(83.8-98.2)$ & $77.8(52.4-93.6)$ & $94.9(85.9-98.9)$ \\
NSE & $100(80.5-99.9)$ & $45(32.1-58.4)^{*}$ & $34(21.2-48.8)$ & $100(87.2-100)$ \\
Algorithm & $86.7(59.5-98.3)$ & $96.6(88.3-99.6)$ & $86.7(59.5-98.3)$ & $96.6(88.3-99.6)$ \\
\hline
\end{tabular}

$\mathrm{NPV}=$ negative predictive value; NSE = neuron-specific enolase; PPV = positive predictive value; proGRP = progastrin-releasing peptide; $\mathrm{Sn}=$ sensitivity; $\mathrm{Sp}=$ specificity.

*Exact McNemar's test $p<0.001$.

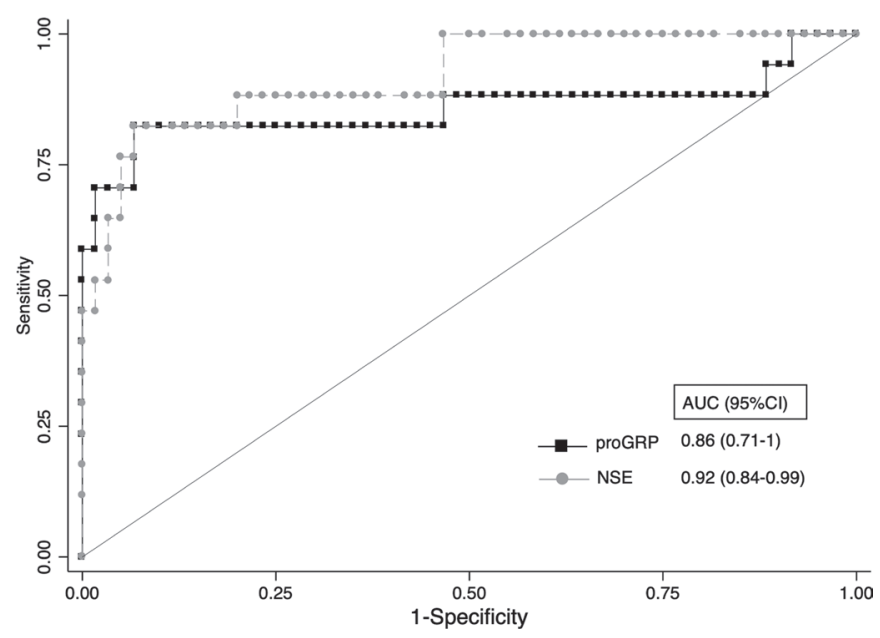

Fig. 3 - Receiver operating characteristics (ROC) curves of proGRP and NSE. NSE = neuron-specific enolase; proGRP = progastrin-releasing peptide. Area under the curve (AUC) were reported.

proGRP appeared to be a promising marker for SCLC, with a sensitivity of $71.6 \%$ and a specificity of $92.1 \%$ (21). However, the poor pooled estimates of sensitivity, the wide range of sensitivity and specificity estimates across studies and the high degree of inconsistency made the conclusions of the meta-analysis weak.

The levels of six tumor markers, CYFRA21-1, CEA, NSE, CA125, proGRP and SCC, were evaluated in 392 Chinese patients affected by lung cancer (including 308 with NSCLC and 84 with SCLC), in 116 patients with benign lung diseases and in 144 healthy controls (22). The results showed that the levels of NSE and proGRP were significantly higher in the SCLC group than in the NSCLC group and that the sensitivity (at 95\% specificity) of NSE, proGRP and the combination of the two markers for differential diagnosis of NSCLC and SCLC was $71.9 \%, 90.6 \%$ and $90.8 \%$, respectively.

In a Chinese study, plasma proGRP levels were prospectively measured in 75 SCLC patients, and they were significantly higher than those of 234 NSCLC patients (1058.0 vs. $37.46 \mathrm{pg}$ / $\mathrm{mL}, \mathrm{p}<0.001$ ) (23). In this study, proGRP showed $87.8 \%$ sensitivity and $91.5 \%$ specificity, at a cutoff level of $65.7 \mathrm{pg} / \mathrm{mL}$. Moreover, change of proGRP levels before and after chemotherapy was analyzed. In patients with SCLC who were followed through the treatment, the median proGRP levels of the responders decreased after chemotherapy $(p<0.001)$.

A retrospective Italian study evaluated serum proGRP levels in 37 patients with SCLC and 28 patients with advanced NSCLC (24). Median proGRP level was 919 pg/mL in SCLC

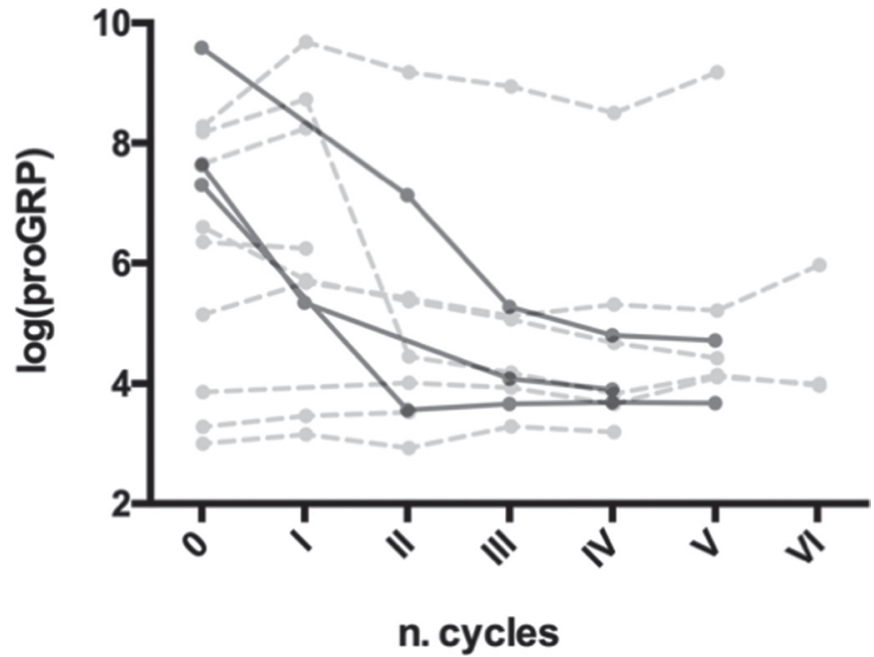

Fig. 4 - Serial measurement of proGRP in SCLC patients and correlation with therapeutic response. Black point with solid line describes patients with complete response to therapy. Gray point with dashed line describes patients with partial response to therapy. proGRP = progastrin-releasing peptide; $\mathrm{SCLC}=$ small cell lung cancer.

and $32 \mathrm{pg} / \mathrm{mL}$ in NSCLC ( $\mathrm{p}<0.0001)$. In this study, proGRP showed $86.4 \%$ sensitivity and $96.4 \%$ specificity, at a cutoff level of $77.8 \mathrm{pg} / \mathrm{mL}$. Moreover, in patients with extended disease, median proGRP was 46 -fold higher than in patients with limited disease ( $p=0.004)$, notwithstanding all the limitations of a statistical analysis conducted over a small-size population.

The results of our study support the use of proGRP at diagnosis to discriminate SCLC from NSCLC or nonmalignant disease. Strengths of our analysis are the prospective design of the study and the inclusion also of health controls to determine the reference values of proGRP in healthy subjects, not evaluated to date in other studies. Furthermore, our study highlights that the diagnostic efficiency of the test is equivalent to that demonstrated by the association of tests included in the diagnostic algorithms, suggesting that proGRP can be considered a valid test to reduce time and costs.

Limitations of our study are the small number of patients enrolled in the study and, in particular, of those with SCLC evaluated with serial measurements of proGRP during treatment. A larger study to confirm the predictive role of proGRP reduction in early identification of responsive SCLC patients to first-line treatment with chemotherapy combined with immunotherapy is planned.

In conclusion, proGRP is an accurate biomarker for the diagnosis of SCLC and for discriminating SCLC from NSCLC. 
Further studies should confirm its utility also for treatment and monitoring of SCLC patients.

\section{Abbreviations}

AUC $=$ area under the curve; $C E A=$ carcinoembryonic antigen; CYFRA 21.1 = cytokeratin 19 fragment 21-1; GRP = gastrin-releasing peptide; IQR = interquartile range; $N A C B$ = National Academy of Clinical Biochemistry; NPV = negative predictive value; $N S C L C=$ non-small cell lung cancer; NSE = neuron-specific enolase; $\mathrm{PPV}=$ positive predictive value; proGRP = precursor of gastrin-releasing peptide; ROC = receiver operating characteristics; $\mathrm{SCC}$ Ag = squamous cell carcinoma antigen; $\mathrm{SCLC}=$ small cell lung cancer.

\section{Acknowledgments}

The authors are grateful to Dr. Alessandra Trocino, Librarian at the IRCCS "G. Pascale" of Naples, Italy, for the excellent bibliographic assistance.

\section{Data Availability}

The data that support the findings of this study are available from the corresponding author on reasonable request.

\section{Disclosures}

Conflict of interest: The authors declare that they have no conflict of interest.

Financial support: This study was supported by the Italian Ministry of Health.

\section{References}

1. Ferlay J, Soerjomataram I, Dikshit R, et al. Cancer incidence and mortality worldwide: sources, methods and major patterns in GLOBOCAN 2012. Int J Cancer. 2015;136(5):E359-E386. CrossRef PubMed

2. Siegel RL, Miller KD, Jemal A. Cancer statistics, 2016. CA Cancer J Clin. 2016;66(1):7-30. CrossRef PubMed

3. Currie GP, Kennedy AM, Denison AR. Tools used in the diagnosis and staging of lung cancer: what's old and what's new? QJM. 2009;102(7):443-448. CrossRef PubMed

4. NCCN Clinical Practice Guidelines in Oncology. Non-small cell lung cancer. V6. Online (Accessed: October 2020).

5. Byers LA, Rudin CM. Small cell lung cancer: where do we go from here? Cancer. 2015;121(5):664-672. CrossRef PubMed

6. Dong $Y$, Zheng $X$, Yang Z, et al. Serum carcinoembryonic antigen, neuron-specific enolase as biomarkers for diagnosis of nonsmall cell lung cancer. J Cancer Res Ther. 2016;12(5) (suppl):34-36. CrossRef PubMed

7. Molina R, Augé JM, Bosch X, et al. Usefulness of serum tumor markers, including progastrin-releasing peptide, in patients with lung cancer: correlation with histology. Tumour Biol. 2009;30(3):121-129. CrossRef PubMed
8. NACB: Practice Guidelines and Recommendations for use of Tumor Markers in the Clinic Lung Cancer (Section 3P), 2006.

9. Molina R, Holdenrieder S, Auge JM, Schalhorn A, Hatz R, Stieber P. Diagnostic relevance of circulating biomarkers in patients with lung cancer. Cancer Biomark. 2010;6(3-4):163-178. CrossRef PubMed

10. Yamaguchi K, Abe K, Kameya T, et al. Production and molecular size heterogeneity of immunoreactive gastrin-releasing peptide in fetal and adult lungs and primary lung tumors. Cancer Res. 1983;43(8):3932-3939. PubMed

11. Wang D, Yeger H, Cutz E. Expression of gastrin-releasing peptide receptor gene in developing lung. Am J Respir Cell Mol Biol. 1996;14(5):409-416. CrossRef PubMed

12. Erisman MD, Linnoila RI, Hernandez O, DiAugustine RP, Lazarus LH. Human lung small-cell carcinoma contains bombesin. Proc Natl Acad Sci USA. 1982;79(7):2379-2383. CrossRef PubMed

13. Moody TW, Pert CB, Gazdar AF, Carney DN, Minna JD. High levels of intracellular bombesin characterize human small-cell lung carcinoma. Science. 1981;214(4526):1246-1248. CrossRef PubMed

14. Lv ShP, Wang Y, Huang L, Wang F, Zhou JG, Ma H. Meta-analysis of serum gastrin-releasing peptide precursor as a biomarker for diagnosis of small cell lung cancer. Asian Pac J Cancer Prev. 2017;18(2):391-397. PubMed

15. Holdenrieder S, von Pawel J, Dankelmann E, et al. Nucleosomes, ProGRP, NSE, CYFRA 21-1, and CEA in monitoring firstline chemotherapy of small cell lung cancer. Clin Cancer Res. 2008;14(23):7813-7821. CrossRef PubMed

16. Wojcik E, Kulpa JK. Pro-gastrin-releasing peptide (ProGRP) as a biomarker in small-cell lung cancer diagnosis, monitoring and evaluation of treatment response. Lung Cancer (Auckl). 2017;8:231-240. CrossRef PubMed

17. Kim HR, Oh IJ, Shin MG, et al. Plasma proGRP concentration is sensitive and specific for discriminating small cell lung cancer from nonmalignant conditions or non-small cell lung cancer. J Korean Med Sci. 2011;26(5):625-630. CrossRef PubMed

18. Oh HJ, Park HY, Kim KH, et al. Progastrin-releasing peptide as a diagnostic and therapeutic biomarker of small cell lung cancer. J Thorac Dis. 2016;8(9):2530-2537. CrossRef PubMed

19. Molina R, Auge JM, Filella $X$, et al. Pro-gastrin-releasing peptide (proGRP) in patients with benign and malignant diseases: comparison with CEA, SCC, CYFRA 21-1 and NSE in patients with lung cancer. Anticancer Res. 2005;25(3A):1773-1778. PubMed

20. Zhou X, Obuchowski N, McClish D. Comparing the accuracy of two diagnostic tests. 2nd ed. Statistical methods in diagnostic medicine. Wiley 2011. CrossRef

21. Yang HJ, Gu Y, Chen C, Xu C, Bao YX. Diagnostic value of pro-gastrin-releasing peptide for small cell lung cancer: a meta-analysis. Clin Chem Lab Med. 2011;49(6):1039-1046. CrossRef PubMed

22. Wang $L$, Wang $D$, Zheng $G$, et al. Clinical evaluation and therapeutic monitoring value of serum tumor markers in lung cancer. Int J Biol Markers. 2016;31(1):e80-e87. CrossRef PubMed

23. Wu XY, Hu YB, Li HJ, et al. Diagnostic and therapeutic value of progastrin-releasing peptide on small-cell lung cancer: a single-center experience in China. J Cell Mol Med. 2018;22(9): 4328-4334. CrossRef PubMed

24. Cavalieri S, Morelli D, Martinetti A, et al. Clinical implications for pro-GRP in small cell lung cancer. A single center experience. Int J Biol Markers. 2018;33(1):55-61. CrossRef PubMed 